\title{
Surgical Timing for Aneurysmal Subarachnoid Hemorrhage: A Meta-Analysis and Systematic Review
}

\author{
Chenhui ZHAO ${ }^{1^{*}}$, Yi WEI ${ }^{*}$ \\ ${ }^{1}$ Shanxi Medical University, The First Hospital, Department of Neurosurgery, Taiyuan, Shanxi Province, China \\ ${ }^{2}$ Shanxi Medical University, The First Hospital, Department of General Surgery, Taiyuan, Shanxi Province, China \\ `These authors contributed equally to this work.
}

\section{ABSTRACT}

\begin{abstract}
AIM: Despite great advances in treatment of aneurysmal subarachnoid hemorrhage (aSAH), yet, a consensus as to the most optimal timing of surgery has not been reached. In order to identify the most suitable time of surgery for aSAH, the authors conducted a meta-analysis and systematic review.
\end{abstract}

MATERIAL and METHODS: PubMed and the Cochrane Library were searched for English-language studies published up to May 2015. Two independent reviewers screened abstracts, reviewed full-text articles and extracted data. Before conducting the metaanalysis, the studies were evaluated for publication bias and heterogeneity. Fixed and random effect models were used to estimate relative risks (RR) and the corresponding 95\% confidence intervals (Cls). Subgroup analysis and sensitivity analysis were also performed.

RESULTS: One randomized controlled trial (RCT) and 33 observational studies of 16,793 participants were included in this paper. The overall methodological quality was satisfying. Results after excluding articles inconsistent with our surgery timing definition showed no significant difference for poor outcome, with early vs intermediate treatment (RR 0.86[0.68,1.09]), early vs late (RR $0.99[0.70,1.40])$. Subgroup analysis based on age showed that early surgery could obtain more favorable outcomes for death rate, with non-early group as reference when age $\geq 50$ years (RR $0.52[0.29,0.93]$ ). When less than 50 years old, patients could benefit more from early intervention for poor outcome, with intermediate group as reference (RR 0.18[0.04,0.78]).

CONCLUSION: Despite the shortcomings of this study, timing of surgery for aSAH did not put a significant impact on overall surgical outcome. But subgroup analysis indicated a trend with more benefits for early treatment. Given the risks of re-bleeding and inpatient stay, early intervention should be performed as soon as possible. However, more randomized trials with long-term followup are necessary, especially in this era of endovascular coiling.

KEYWORDS: Early surgery, Late surgery, Ruptured intracranial aneurysm, Subarachnoid hemorrhage, Timing

\section{INTRODUCTION}

A Ithough intracranial aneurysmal subarachnoid hemorrhage (aSAH) accounts only for $3 \%$ to $4 \%$ of all strokes and $4.4 \%$ of deaths from stroke $(18,50)$, aSAH is a significant health problem, which within 1 month has a mortality rate of nearly $50 \%$, and many patients become care-depen- dent after surgery (19). Therefore, with the economic burdens of aSAH increasing every year, cost effectiveness and preventative strategies have become much more important.

Before the 1970s, it was thought that cerebral edema and cerebral vascular dysregulation after acute aSAH, were associated with early surgery. In order to avoid the unfavorable 
surgical conditions and outcomes, surgery was usually delayed $(13,42)$. However, over time the potential benefits of "early" surgery has gradually begun to be paid attention. In 1990, International Cooperative Trial data demonstrated that overall outcomes of both early and late surgery were largely equivalent $(17,19)$. Since then, surgeons in more and more neurosurgical centers tend to operate "early", even "ultraearly" intervention, to secure the ruptured aneurysm.

Although the intervention intervals towards the treatment of intracranial aSAH has shifted from "delayed" to "early" approach in the past several decades, nevertheless, a consensus as to the most appropriate surgical timing has not still been reached. In order to seek the extremely optimum therapeutic time intervals, we performed a quantitative systematic review. For this purpose, we tried to include as many observational studies as possible that fulfilled a set of minimum requirements on methodological quality.

\section{- MATERIAL and METHODS}

\section{Search Methods}

Pubmed, Cochrane Library, and reviews and reference lists of relevant articles were searched for studies published before May 2015. Search items included: "timing of subarachnoid hemorrhage" or "timing of aSAH" or "early surgery of subarachnoid hemorrhage" or "late surgery of subarachnoid hemorrhage" or "ruptured intracranial aneurysm".

\section{Selection Criteria}

We selected studies as follows:

\section{Admission conditions have to be provided}

2. At least two periods of our timing definition have to be existed

3. Certain outcomes of the participants have to be mentioned; our outcome was defined according to Glasgow Outcome Score (GOS)

4. Relative risk (RR) and $95 \%$ Confidence intervals (Cls)

\section{Data Extraction}

Two authors (Chen-Hui ZHAO and Yi WEI) independently extracted data from each study. The following information was recorded from each study:

1. Clearly defined and evaluated exposure to the timing of surgery. We defined surgery within 72 hours after the onset of aSAH as "early surgery stage", after 3 days as "nonearly surgery stage", 4-7 days as "intermediate stage" and after 7 days as "late stage", according to the category described in most included studies.

2. Death or poor outcome incidence as the outcome of interest. We defined death, vegetative state and severe disability as "poor outcome" or "unfavorable outcome" according to GOS, while good recovery and moderate disability as "favorable outcome".
3. Clinical condition at admission was divided into two categories: Hunt-Hess I-III was defined as "good clinical condition" and Hunt-Hess IV-V as "poor condition". In addition, World Federation of Neurosurgical Societies scale (WFNS $(28,38)$ ) I-III, Botterell I-II and GCS (40) 13-15 were considered as Hunt-Hess I-III.

4. Study design,

5. First author's last name, year of publication and country of population studies, mean age, sex, location, re-bleeding.

\section{Quality Assessment}

In order to ensure the reliability of the chosen articles, including those that some authors considered controversial, the quality of each study was assessed by two authors (Yi WEI and Chen-Hui ZHAO). The included randomized controlled trial (RCT) was assessed based on the Cochrane handbook and the methodological quality of the included cohort studies was assessed by the New Castle-Ottawa Scale (NOS). A score of $\geq 7$ was suggestive of a high-quality study. Any discrepancies were addressed by a joint re-evaluation of the original article with a third author.

\section{Data Synthesis and Analysis}

Review Manager (RevMan) software (Version 5.0; Cochrane Collaboration, Oxford, UK) was used to perform data analysis. The heterogeneity among all studies was assessed by Cochran $Q$ and $I^{2}$ statistics. For the $Q$ statistic, a $p$ value $<0.10$ was considered statistically significant; for the $\mathrm{I}^{2}$ statistic, a value $>50 \%$ was considered a measure of severe heterogeneity. The random-effect models were used when $\mathrm{I}^{2}>50 \%$, or fixedeffect models were performed. Subgroup analyses were used to investigate the source of heterogeneity.

Publication bias was assessed using the Egger's regression asymmetry test and the Begg's test, and qualitatively assessed by visual inspection of funnel plots. Sensitivity analysis was also used to evaluate the influence of individual studies by estimating the average RR in the absence of each study. All of these analyses were achieved by Stata software (Version 9.0; Stata Corporation, College Station, TX, USA).

\section{RESULTS}

A total of 1,038 articles were identified during our initial search, including 11 additional articles extracted from the reference list. 29 articles were removed due to being duplicates, which left 1,009 for article review. 952 articles were found to be ineligible based on irrelevant titles and abstracts. After detailed evaluation of the remaining 57 articles, $1 \mathrm{RCT}$ (34) and 33 cohort studies $(1,4-6,9-12,14,16,17,20-26,28,30,31,33,36-$ $38,40,41,43,44,46,47,49,52)$ were included for reasons described in Figure 1.

Thirty-four studies, which were published between 1978 and 2015 , contributed to this analysis. A total of 16,793 participants were involved in this paper, and 870 of these were in poor clinical condition at admission. Table I displayed the characteristics of all the included studies. The qualities of studies were moderate to high. $72.7 \%$ of all the included 
studies were considered to be of high-quality. Although most studies used the category interval described in the part of method, some studies' definition of surgery timing was still not uniform.

In 11 studies, early surgery stage was defined as five different categories in these studies' context: $0-1$ days (36), 0-2 days $(4,10,23,40,44), 0-4$ days $(9,12,14,21,26), 0-7$ days $(30)$, undefined (41). In the same 11 studies, non-early stage was defined as 9 different categories: after 1 day (36), after 2 days $(4,10,23,40)$, after 4 days $(9)$, after 6 days $(14,21)$, after 7 days (30), after 8 days (12), after 9 days (26), after 10 days (44) and undefined (41).

In 4 studies, intermediate surgery was defined as 2 categories: 4-6 days $(17,28), 3-7$ days $(10,40)$. In 10 studies, late surgery was defined as 5 categories: after 6 days $(14,21,28)$, after 8 days (12), after 9 days $(5,26)$, after 10 days $(9,37,44,49)$, after 11 days (4) and after 12 days (47).

At first, according to the timing definition of original texts, the relationship between the prognosis and surgery timing was investigated (Table II). It indicated that there were no statistically significant differences among early, intermediate and late surgery for poor outcome. For death rate, it shown no significant differences among early, non-early and late surgery. But intermediate surgery may get a better outcome on mortality (RR 1.43[1.02, 2.01], $p=0.04, \mathrm{I}^{2}=65 \%$ ), as shown in Figure 2. Then, in order to investigate the most optimum surgery time for aSAH more precisely, we excluded articles inconsistent with our surgery timing definition. It manifested no statistically significant differences among early, intermediate and late surgery both for poor outcome and mortality (Table II). In addition, given the fact of higher disability rate and mortality associated with poor admission condition, we made a further analysis for poor-grade aSAH patients at admission. It denoted that there was no significant association between surgery timing and the prognosis in patients with poorgrade aSAH clinical condition (Table II). To further investigate the source of heterogeneity, subgroup analysis should be completed towards age, sex, location and size. However, for the lack of information on these aspects, we could only do subgroup analysis based on age (Table III). According to age, the RR of poor outcome for patients for early surgery, with intermediate surgery as a reference point, was $0.18[0.04,0.78]$ $(p=0.02)$ when age $<50$ years. The RR of death rate for patients undergone early surgery, with non-early surgery as a reference point, was $0.52[0.29,0.93](p=0.03)$ when age $\geq 50$ years.

When there were more than 10 included articles in each comparison (Table II), we performed publication bias tests. No publication bias was observed using Begg's value $(p=0.398)$ and Egger's test $(p=0.501)$, in the group with comparison between early and intermediate surgery for poor outcome, which included 30 articles (Table II). No publication bias was observed in other comparison groups with the funnel plot showing no obvious asymmetry. Each study was excluded and its effect on the main summary was estimated to assess whether any one study had a dominant effect on the metaanalytic RR. This analysis showed no significant variation in combined RR by excluding any of the studies when the random-effects model was used.

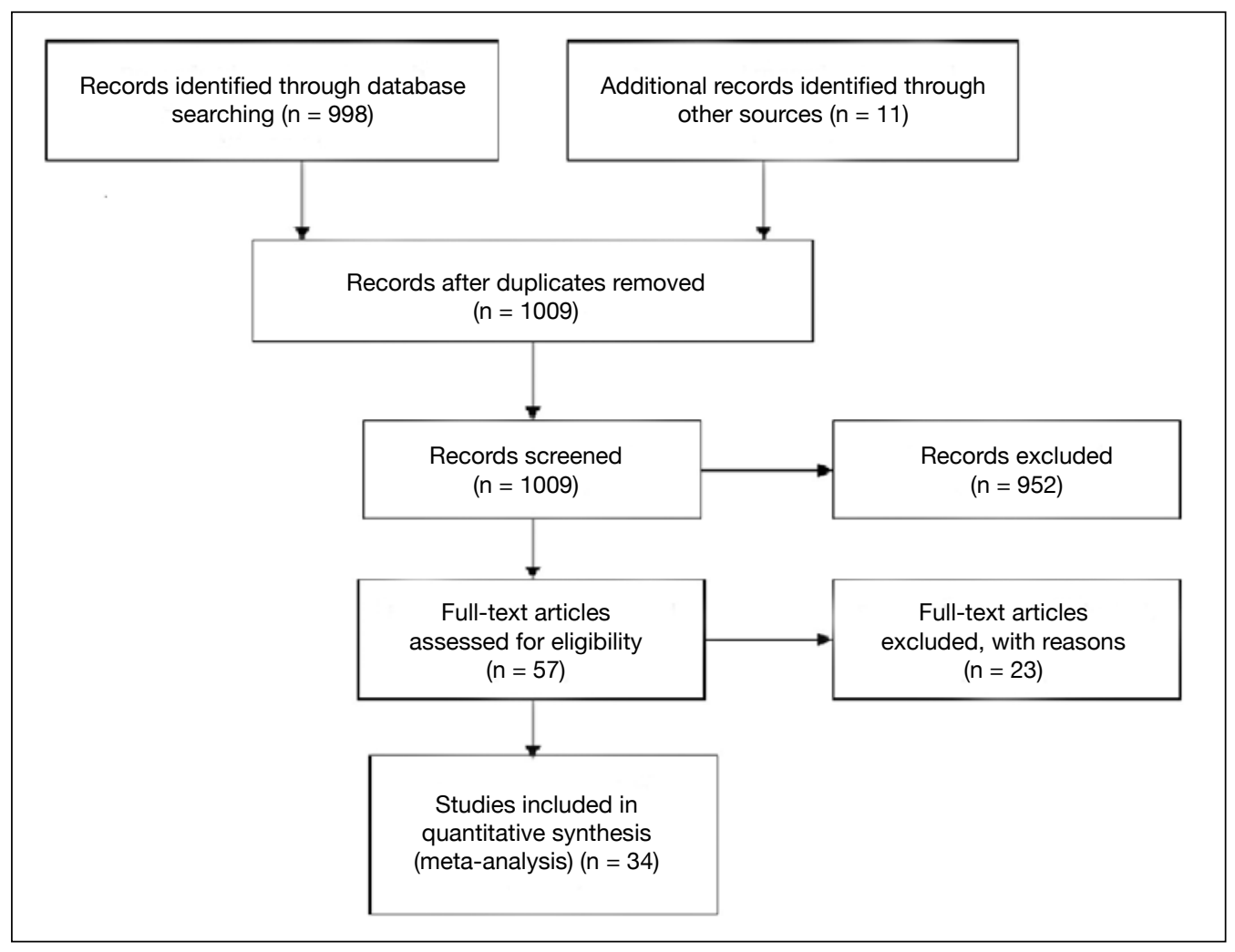

Figure 1: PRISMA 2009 Flow Diagram of included studies. 
Table I: Characteristics of Included Studies

\begin{tabular}{|c|c|c|c|c|c|c|c|c|}
\hline Series & TIM & To & D & PO & $\mathbf{A}$ & Male \% & Country & Reb \\
\hline \multirow{2}{*}{ Qian Z 2014} & $\mathrm{E}$ & 331 & 17 & 41 & 56 & 44 & \multirow{2}{*}{ China } & \multirow{2}{*}{ NR } \\
\hline & $\mathrm{NE}$ & 433 & 25 & 77 & 55 & 43. & & \\
\hline \multirow{2}{*}{ Mahaney KB 2011} & $\mathrm{E}$ & 679 & \multicolumn{2}{|c|}{117} & 51 & 35 & \multirow{2}{*}{ America } & \multirow{2}{*}{ NR } \\
\hline & $\mathrm{NE}$ & 320 & \multicolumn{2}{|c|}{223} & 53 & 37 & & \\
\hline \multirow{2}{*}{ Golchin N 2012} & $E$ & 50 & \multicolumn{2}{|c|}{17} & 48 & 40 & \multirow{2}{*}{ Iran } & \multirow{2}{*}{$\begin{array}{l}8 \\
5\end{array}$} \\
\hline & $\mathrm{NE}$ & 20 & & & 50 & 45 & & \\
\hline \multirow{2}{*}{ Chyatte D 1988} & $E$ & 85 & 8 & 13 & 48 & 40 & \multirow{2}{*}{ America } & \multirow{2}{*}{ NR } \\
\hline & $\mathrm{NE}$ & 133 & 15 & 14 & 51 & 45 & & \\
\hline \multirow{2}{*}{ Sano K. 1994} & $E$ & 447 & 76 & 51 & \multirow{2}{*}{$N R$} & \multirow[b]{2}{*}{ NR } & \multirow{2}{*}{ Japan } & \multirow{2}{*}{171} \\
\hline & $\mathrm{NE}$ & 852 & 45 & 58 & & & & \\
\hline \multirow{2}{*}{ Lawson MF 2010} & $E$ & 102 & 26 & 9 & 58 & 30.4 & \multirow{2}{*}{ America } & $N R$ \\
\hline & $\mathrm{NE}$ & 14 & 2 & 4 & 53 & 35.7 & & NR \\
\hline & $E$ & 331 & 55 & 34 & 52 & 36.3 & & NR \\
\hline Ross N 2002 & $\mathrm{NE}$ & 219 & 40 & 22 & 55 & 29.6 & England & $\mathrm{NR}$ \\
\hline & $E$ & 464 & 91 & 48 & NR & NR & & $\mathrm{NR}$ \\
\hline Miyaoka M 1993 & $\mathrm{NE}$ & 823 & 84 & 116 & NR & NR & Japan & $\mathrm{NR}$ \\
\hline & $E$ & 71 & 4 & 2 & 43 & 41 & Finlond & 2 \\
\hline Ohman J 1989 & $\mathrm{NE}$ & 140 & 13 & 16 & 45 & 54 & Finland & 14 \\
\hline & $E$ & 1373 & & & 51 & 37.2 & & 8 \\
\hline Dorhout Mees SM 2012 & $\mathrm{NE}$ & 733 & & & 53 & 38.3 & Netherlands & 20 \\
\hline & $E$ & 1478 & 186 & NR & 10 & NR & Amoriso & 9 \\
\hline Haley EC, Jr. 1992 & $\mathrm{NE}$ & 1354 & 126 & NR & 49 & NR & America & 28 \\
\hline Kaccoll NE 1081 & $\mathrm{E}$ & 249 & 85 & 56 & NR & 36 & Amorica & 31 \\
\hline Kassell NF 1981 & $\mathrm{NE}$ & 262 & 62 & 62 & NR & 36 & Amerıca & 14 \\
\hline & $E$ & 182 & & & NR & & & \\
\hline Seifert V 1988 & $\mathrm{NE}$ & 221 & & & NR & 40 & Germany & NR \\
\hline & $E$ & 7 & & & & & & \\
\hline Dorsch NW 1984 & $\mathrm{NE}$ & 143 & & & 45 & 39 & Australia & NR \\
\hline Aho K 1902 & $E$ & 22 & 0 & 3 & 51 & 23 & lanan & NR \\
\hline Abe K 1992 & $\mathrm{NE}$ & 15 & 5 & 7 & 55 & 47 & Japan & NR \\
\hline & $E$ & 190 & 60 & 40 & NR & & & \\
\hline Taneda M 1982 & $\mathrm{NE}$ & 61 & 33 & 49 & NR & 39 & Japan & 25 \\
\hline & $E$ & 27 & 3 & 2 & 51 & 30 & Amorico & 0 \\
\hline Kassell NF 1981 & $\mathrm{NE}$ & 24 & 10 & 4 & 50 & 17 & America & 7 \\
\hline & $E$ & 59 & 21 & 13 & 57 & $\mathrm{NR}$ & & NR \\
\hline Yamamoto K 1992 & $\mathrm{NE}$ & 46 & 42 & 3 & 59 & NR & Japan & NR \\
\hline Kalcmi Y 1007 & $E$ & 16 & 0 & 0 & 56 & 210 & lanon & NR \\
\hline Kawakamı Y $798 /$ & $\mathrm{NE}$ & 6 & 0 & 0 & 56 & 31.8 & Japan & NR \\
\hline & $E$ & 100 & 20 & NR & NR & NR & Amorico & NR \\
\hline Millhorat IH 1986 & $\mathrm{NE}$ & 100 & 65 & 4 & NR & NR & Amerıca & NR \\
\hline & $E$ & 31 & 2 & 2 & NR & NR & & NR \\
\hline Ljunggren B 1982 & $\mathrm{NE}$ & 14 & 1 & 1 & NR & NR & Sweden & NR \\
\hline & $\mathrm{E}$ & 85 & & & NR & 35 & & 10 \\
\hline van der Jagt M 2009 & $\mathrm{NE}$ & 118 & & & NR & 28 & Netherlands & 20 \\
\hline
\end{tabular}


Table I: Cont.

\begin{tabular}{|c|c|c|c|c|c|c|c|c|}
\hline Series & TIM & TO & D & PO & $\mathbf{A}$ & Male \% & Country & Reb \\
\hline \multirow{2}{*}{ Tamasauskas A 2000} & $E$ & 65 & 34 & 15 & NR & \multirow{2}{*}{45.6} & \multirow{2}{*}{ Lithuania } & \multirow{2}{*}{63} \\
\hline & NE & 346 & 49 & 98 & NR & & & \\
\hline \multirow{2}{*}{ Ferch R 2003} & $E$ & 50 & \multicolumn{2}{|c|}{27} & NR & NR & \multirow{2}{*}{ Italy } & \multirow{2}{*}{ NR } \\
\hline & NE & 47 & & & NR & NR & & \\
\hline \multirow{2}{*}{ Haibin T 2014} & $E$ & 39 & 2 & 8 & 49 & 62.5 & \multirow{2}{*}{ China } & NR \\
\hline & $\mathrm{NE}$ & 28 & 3 & 16 & 55 & 38.2 & & 3 \\
\hline \multirow{2}{*}{ Phillips TJ, 2011} & $E$ & 230 & 8 & 8 & 52 & 48 & \multirow{2}{*}{ Australia } & NR \\
\hline & NE & 229 & 15 & 15 & 54 & 52 & & NR \\
\hline \multirow{2}{*}{ Baltsavias GS 2000} & $E$ & 107 & 10 & 20 & \multirow{2}{*}{50.5} & \multirow{2}{*}{34.3} & \multirow{2}{*}{ England } & 21 \\
\hline & NE & 220 & 13 & 34 & & & & 28 \\
\hline \multirow{2}{*}{ Nieuwkamp DJ 2005} & $E$ & 276 & 93 & NR & \multirow{2}{*}{52} & \multirow{2}{*}{31} & \multirow{2}{*}{ Netherlands } & \multirow{2}{*}{ NR } \\
\hline & NE & 135 & 50 & NR & & & & \\
\hline \multirow{2}{*}{ Dorsch NW 1989} & $E$ & 111 & 10 & 19 & NR & NR & \multirow{2}{*}{ Australia } & NR \\
\hline & $\mathrm{NE}$ & 203 & 10 & 24 & NR & $\mathrm{NR}$ & & $\mathrm{NR}$ \\
\hline \multirow{2}{*}{ Tucker WS 1987} & $E$ & 49 & 4 & 5 & 50.8 & NR & \multirow{2}{*}{ Canada } & 8 \\
\hline & NE & 144 & 12 & 23 & 47.2 & NR & & 18 \\
\hline \multirow{2}{*}{ Weir B 1981} & $E$ & 95 & 56 & NR & NR & NR & \multirow{2}{*}{ Canada } & NR \\
\hline & $\mathrm{NE}$ & 129 & 53 & NR & NR & NR & & NR \\
\hline \multirow{2}{*}{ Kayama T 1978} & $E$ & 54 & 9 & 26 & NR & NR & \multirow{2}{*}{ Japan } & $\mathrm{NR}$ \\
\hline & $\mathrm{NE}$ & 89 & 18 & 45 & NR & NR & & NR \\
\hline \multirow{2}{*}{ Lee KC 1991} & $E$ & 141 & 15 & 22 & NR & NR & \multirow{2}{*}{ Korea } & \multirow{2}{*}{4} \\
\hline & NE & 580 & 16 & 29 & NR & NR & & \\
\hline OR 0 o 01 & $\mathrm{E}$ & 135 & 9 & NR & 51 & 40.7 & & NR \\
\hline Dainayrak s zol1 & $\mathrm{NE}$ & 24 & 6 & NR & 56 & 66.7 & Iurkey & NR \\
\hline
\end{tabular}

$\mathbf{T I M}=$ Timing of surgery, $\mathbf{T O}=$ Total number $\boldsymbol{D}=$ Death number, $\mathbf{P O}=$ Poor outcome number, $\boldsymbol{A}=$ Age, $\boldsymbol{R e b}=$ Re-bleeding, $\boldsymbol{E}=$ Early surgery 0 -3days, $\mathbf{N E}=$ Not early surgery $>3$ days, $\mathbf{N R}=$ Not reported.

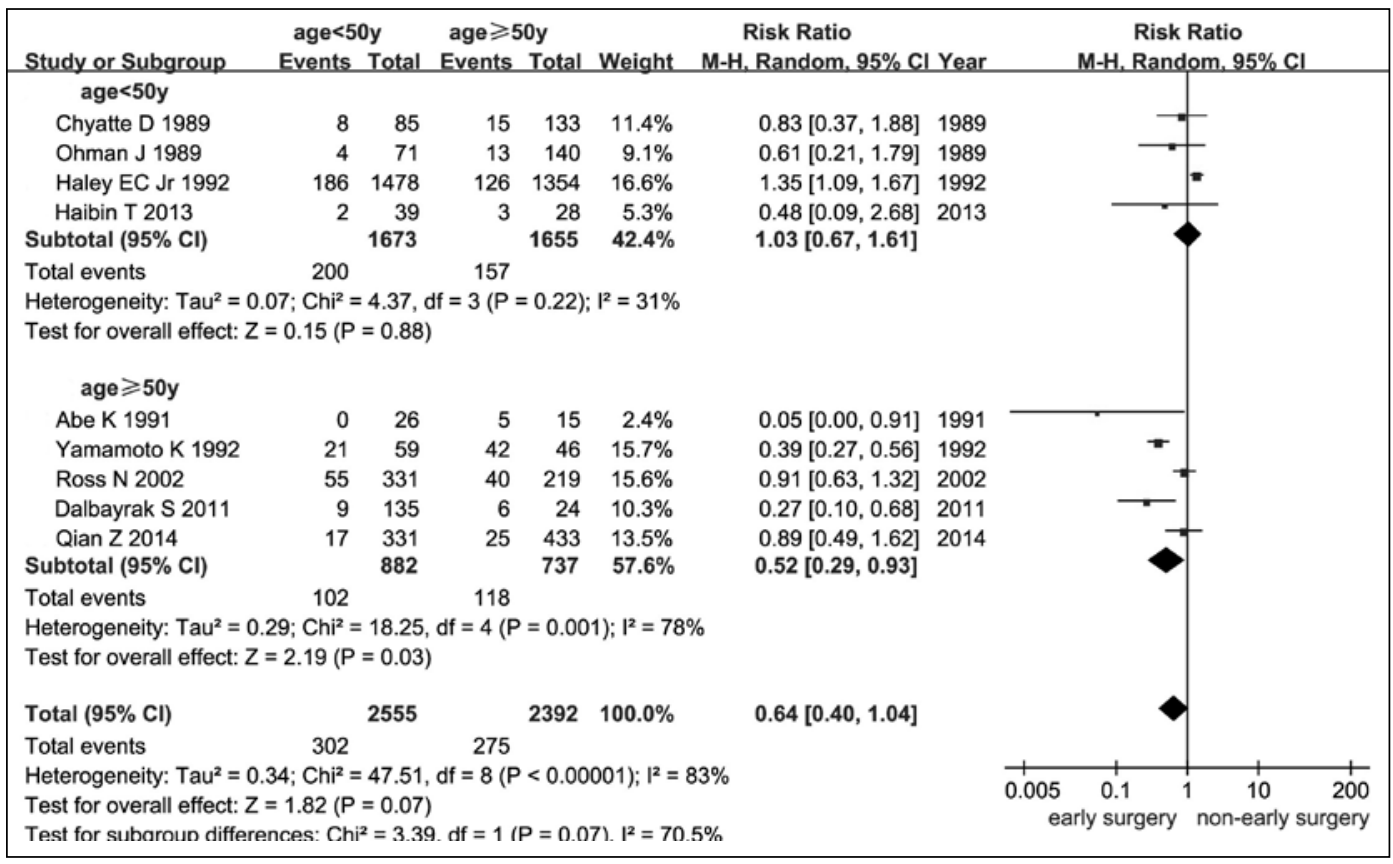

Figure 2: Early surgery versus intermediate surgery for death rate. 
Table II: The RR Estimates and 95\% Cl

\begin{tabular}{|c|c|c|c|c|c|}
\hline & $\begin{array}{l}\text { Intervention } \\
\text { Group (n) }\end{array}$ & Participants & $\begin{array}{l}\text { RR(M-H,Random } \\
\quad 95 \% \mathrm{Cl})\end{array}$ & $\mathbf{I}^{2}$ & $\mathbf{p}$ \\
\hline \multicolumn{6}{|c|}{ Results according to the surgery timing definition of original texts } \\
\hline Early vs. non-early surgery for poor outcome & 30 & 13,378 & $0.87[0.65,1.15]$ & $92 \%$ & 0.32 \\
\hline Early vs. non-early surgery for death & 26 & 12,354 & $1.05[0.77,1.44]$ & $90 \%$ & 0.75 \\
\hline Early vs. intermediate surgery for death & 6 & 3,388 & $1.43[1.02,2.01]$ & $65 \%$ & 0.04 \\
\hline Early vs. late surgery for poor outcome & 18 & 6,920 & $0.73[0.43,1.24]$ & $96 \%$ & 0.24 \\
\hline Early vs. late surgery for death & 13 & 6,267 & $1.28[0.79,2.09]$ & $90 \%$ & 0.31 \\
\hline \multicolumn{6}{|c|}{ Results after excluding articles inconsistent with our surgery timing definition } \\
\hline Early vs. intermediate surgery for death & 4 & 810 & $1.85[0.93,3.70]$ & $73 \%$ & 0.08 \\
\hline Early vs. late surgery for poor outcome & 9 & 2,749 & $0.99[0.70,1.40]$ & $74 \%$ & 0.95 \\
\hline Early vs. late surgery for death & 7 & 1981 & $1.18[0.65,2.14]$ & $74 \%$ & 0.60 \\
\hline $\begin{array}{l}\text { Early vs. non-early surgery for poor outcome of } \\
\text { poor clinical condition }\end{array}$ & 9 & 870 & $1.09[0.87,1.35]$ & $16 \%$ & 0.46 \\
\hline $\begin{array}{l}\text { Early vs. non-early surgery for death of poor } \\
\text { clinical condition }\end{array}$ & 9 & 870 & $1.02[0.86,1.22]$ & $47 \%$ & 0.80 \\
\hline
\end{tabular}

\section{DISCUSSION}

As a disease with a high death rate in neurosurgery, intracranial aSAH with different severity suffers a lot of patients in various cases. Yet, when dealing with numbers of individuals, the most optimal timing for clipping or endovascular coiling has not still been determined since decades ago. In order to explore the extremely opportune timing for aSAH, a large number of clinical trials have been conducted throughout the world. But the results and conclusions they reached, to a large extent, varied diversely from each other. For the sake of investigating this question remaining still controversial, we performed a meta-analysis towards the extremely optimum timing of aSAH surgery. Thirty-three cohort studies and 1 RCT study with 16,793 patients contributed to this analysis.

The results demonstrated that there was no statistically significant association for both mortality and poor outcome incidence, among early, intermediate and late surgery, which were in consistent with the opinions from recent increasing observational studies including the single available RCT. That is to say, the timing of surgery did not have a significant impact upon surgical outcome and prognosis. It did not increase mortality and poor outcome incidence during the intermediate interval for surgical intervention. In other words, surgical treatment can also be performed safely in this particular period. The subgroup analysis based on age indicated a trend of more benefit for early intervention. Taking the risks of re-bleeding and hospital in stay time into consideration, the authors' conclusion is that endovascular coiling or surgical clipping should be carried out as soon as possible in patients with ruptured aSAH. However, this study differs in several ways from the results of the previous meta-analysis including 11 studies in 2002 by de Gans et al. that patients in good clinical admission condition could reap more benefit with early or intermediate surgery than late surgery. For patients in poor admission condition, it suggested only a tendency of this influence (7). Thus, larger sample sizes of contemporary, randomized and prospective trials are required to recognize the advantages and disadvantages of early, intermediate and late surgery in aSAH patients.

\section{"Intention to Treatment" and "on Treatment"}

The accuracy of relationship between surgical timing intervals and treatment outcome may be directly influenced by the number of patients and events during data extraction. Thus in order to reduce this possible bias, we tried to pick up the whole number of patients to our best who had intended to receive surgery ("intention to treatment"), no matter whether or not they were alive at the planned surgery time, instead of just drawing the number of those who managed to survive till surgery ("on treatment") (33). Practitioners and study designers in most original trials, allocated those "unoperated" 
Table III: Subgroup Analysis according to Age and Clinical Condition at Admission

\begin{tabular}{|c|c|c|c|c|c|}
\hline & $\begin{array}{c}\text { Intervention } \\
\text { Group (n) }\end{array}$ & Participant & $\begin{array}{c}\text { RR (M-H, Random } \\
95 \% \mathrm{Cl})\end{array}$ & $\mathbf{I}^{2}$ & $\mathbf{p}$ \\
\hline \multicolumn{6}{|c|}{ Early vs. non-early surgery for poor outcome } \\
\hline$<50 y$ & 4 & 689 & $0.59[0.27,1.28]$ & $69 \%$ & 0.18 \\
\hline$\geq 50$ y & 7 & 2,888 & $0.70[0.35,1.41]$ & $95 \%$ & 0.32 \\
\hline \multicolumn{6}{|c|}{ Early vs. non-early surgery for death } \\
\hline$<50$ y & 4 & 3,328 & $1.03[0.67,1.61]$ & $31 \%$ & 0.88 \\
\hline$\geq 50 y$ & 5 & 1,619 & $0.52[0.29,0.93]$ & $78 \%$ & 0.03 \\
\hline \multicolumn{6}{|c|}{ Early vs. Intermediate surgery for poor outcome } \\
\hline$<50 y$ & 1 & 141 & $0.18[0.04,0.78]$ & - & 0.02 \\
\hline$\geq 50 \mathrm{y}$ & 1 & 312 & $0.93[0.59,1.49]$ & - & 0.77 \\
\hline \multicolumn{6}{|c|}{ Early vs. Intermediate surgery for death } \\
\hline$<50 \mathrm{y}$ & 1 & 141 & $0.99[0.26,3.79]$ & - & 0.98 \\
\hline$\geq 50 \mathrm{y}$ & 0 & 0 & Not estimable & - & NA \\
\hline \multicolumn{6}{|c|}{ Early vs. late surgery for poor outcome } \\
\hline$<50 y$ & 2 & 276 & $0.83[0.34,2.02]$ & $18 \%$ & 0.68 \\
\hline$\geq 50 \mathrm{y}$ & 3 & 1,023 & $0.89[0.70,1.13]$ & $0 \%$ & 0.33 \\
\hline \multicolumn{6}{|c|}{ Early vs. late surgery for death } \\
\hline$<50 \mathrm{y}$ & 2 & 276 & $0.64[0.30,1.38]$ & $0 \%$ & 0.26 \\
\hline$\geq 50 y$ & 2 & 648 & $0.83[0.47,1.49]$ & $0 \%$ & 0.54 \\
\hline \multicolumn{6}{|c|}{ Early vs. non-early surgery of poor clinical condition for poor outcome } \\
\hline$\geq 50$ y & 2 & 251 & $0.82[0.63,1.06]$ & $50 \%$ & 0.13 \\
\hline$\geq 50 \mathrm{y}$ & 1 & 14 & $0.19[0.03,1.28]$ & - & 0.09 \\
\hline
\end{tabular}

RR: Relative risk, Cl: Confidence interval, y: Years, $\boldsymbol{M}-\boldsymbol{H}$ : Mantel-Haenszel ratio.

patients, who were trapped in certain type of admission condition to the most frequent timing intervals, according to the individual admission grade, apart from its hospital management strategy. Of course, there remains a few studies who only put their limited interest in patients receiving surgical treatment. By fulfilling such a principle in this analysis, we took patients who had deteriorated or died before the planned time into consideration as much as possible.

\section{Coiling and Clipping}

It is inevitable for conventional clipping to perform surgical dissection or retraction, which is likely to cause direct damage to the tissue of brain. On the contrary, taking the natural advantages of its interventional techniques, endovascular coiling can perfectly avoid such confusion, and thus may have an important influence on the overall outcome (27). The application of detachable coils has become more and more popular since its first introduction (48). Whereas, owing to insufficient endovascular equipment and conservative understandings, it was receiving open craniotomy for surgical clipping that many patients continued to choose. Taken all these factors into account, from the original trials we could not extract sufficiently detailed information concerning surgical approaches for subgroup analysis. However, according to the result of a meta-analysis in terms of neurosurgical clipping and coiling towards the cerebral vasospasm rate after aSAH, it disclosed no statistically significant difference between these two approaches, although there was a trend of higher rate of vasospasm for clipping (8) (RR1.2[0.99-1.48]). On the contrary, an available data from another meta-analysis showed a reduction of poor outcome rate for good clinical patients under the utilization of endovascular coiling, when both approaches were considered suitable for the aSAH cases (48). Apart from blood and its products flowing into subarachnoid space, craniotomy for surgical clipping can also lead to the surging of free radicals and arachidonic acid and high risk of spastic response of brain vessels related with surgical manipulation, all of which may promote or 
result in exacerbation of vasospasm (8). Besides, sometimes it is rather difficult to expose the aneurysmal neck during conventional open craniotomy clipping, and aneurysm rupture may occur owing to the temporary jam of the parent vessel, which is responsible for higher mortality. At the same time, what remains a major concern for endovascular coiling is that aneurysm reopening, in the long-term follow up, may occur from the impaction of the coils (48). Thus it still demands further studies focusing on this discrepancy.

\section{Ultra-Early Intervention}

Due to the lack of adequate information concerning other confounders, we could only make a subgroup analysis based on age, which cannot completely eliminate the significant heterogeneity. A trend of an improving outcome was observed with early surgery in this subgroup analysis, although the overall results as mentioned above disclosed no significantly difference towards timing intervals. No publication bias was observed according to Begg's and Egger's test in this systematic review, and the funnel plot showed no obvious asymmetry. Nowadays, more and more centers have become preferable to operate surgery as early as possible, even within the first 24 hours of the onset. From the standpoint of theoretical perspective, earlier intervention ought to be associated with a lower re-bleeding incidence, which is likely to improve the overall outcome. It is reported that the re-bleeding incidence within the first 24 hours is the highest which ranges from $4.1 \%$ to $17.3 \%$ in multiple retrospective studies. Phillips et al. reached to the conclusions that ultraearly intervention within 24 hours window could reap an improved clinical benefit than later after 24 hours. It is also noted that compared with clipping, such benefit is more significant for endovascular coiling (36). Nevertheless, it should also be mentioned for some disadvantages, including greater possibility of perioperative complications and increasing risk of cerebral vascular dysfunction(especially after the third day) (29). Wong et al. reported that ultra-early treatment may put a positive influence on overall outcome and decrease the clinical re-bleeding risk in poor-grade aSAH patients (51), which is similar to the results obtained by Qian et al. (37).

As the understanding of the SAH pathophysiology increases, it becomes gradually acknowledged that "early brain injury" (EBI) plays a major role in SAH-induced injury $(36,52,53)$. This concept was firstly introduced in 2004 by Kusaka et al, which refers to the global brain injury that begins to initiate the moment aneurysms rupture within the primary 72 hours before vasospasm develops $(39,53)$. Furthermore, a number of researchers believe that a series hemodynamic changes within the first 24 hours may result in neurobiology devastating cascade (39). That is to say, during this first 72 hours, apart from intracranial pressure (ICP) dysregulation, there exists a significant imbalance of cerebrospinal fluid (CSF), cerebral perfusion pressure (CPP) and cerebral auto-regulation, which may trigger a quantity of substantial devastating pathologic responses, including blood brain barrier (BBB) dysfunction, inflammation, oxidative stress, apoptosis, ionic imbalance, cortical spreading depolarization, micro-thrombosis and so on $(3,32,45)$. Early surgery including ultra-early intervention may have an important impact on this pathological process, thus indicates a different prognosis.

\section{Poor Clinical Condition at Admission}

Though the clinical outcome and prognosis for aSAH patients has improved greatly in recent years, which may mainly attribute to developed microsurgical equipment and improved neurointensive care, poor clinical admission condition patients are still suffering from higher mortality. In thousands of hundreds patients with aSAH, the poor-grade cases takes the proportion from $24 \%$ to $45 \%$, and the clinical outcome of this population remains dismal (15). It is also reported that the re-bleeding rate is actually higher compared with good-grade (15).

Subgroup analysis results found no significant difference in overall outcome between early and non-early groups for patients who had high Hunt-Hess scores on admission. In this kind type of patients, factors which may be linked to the initial poor condition still remains unidentified (54). Several researchers have discovered that among these patients, abnormality of intractable ICP is accomplished with a poor outcome (35). However, how the clinical outcome and prognosis of aSAH patients with high Hunt-Hess scores are influenced by the dysregulation of ICP hasn't been demonstrated. De Gans et al. came to the conclusions that for patients with high Hunt-Hess scores at admission, there was only a trend of more benefit in the early and intermediate surgery, compared with late group (7). While Lawson et al. pointed out that Hunt-Hess grade on admission and age were two important factors in SAH patients undergone coiling which could help predict the poor outcome and death incidence (24). Data from Nieuwkamp et al. also indicated patients with aSAH admitted in poor condition may reap some more benefit from early intervention (33). Ideally, evidence for the most optimum timing of surgery in such a particular situation should be obtained from a new randomized controlled trial, especially in this epoch of endovascular coiling (54).

\section{Strengths}

There hasn't been a meta-analysis and systematic review based on large population about the optimal timing for aSAH since the last decade. According to our search results, this article contains the most participants and more advanced studies compared with the previous reviews. Besides, the single available RCT was of satisfying Jadad scores, and $72.7 \%$ of the cohort studies included were of high quality. Consequently, the design of study and cases selection were generally comparable, and the fundamental characteristics of prognosis were well-balanced. What's more, there are 9 studies with 870 participants, which have detailed information about poor outcome and death rate for severe patients with high Hunt-Hess scores. Thus, for poor -grade (Hunt-Hess grade IV and $\mathrm{V}$ ) aSAH patients, we can make cautious comparison and analysis. This will not only help us get a better understanding of important prognosis predictors in patients with high HuntHess scores, but also contribute to guiding the strategy of future treatment. In addition, inclusion criteria standards were strictly enacted and surgery timing intervals were also defined 
vigorously. No publication bias was observed and sensitivity analysis identified the stability of results. All these factors support the validity of this meta-analysis.

\section{Limitations}

Of course, several weaknesses are inherent in this study. First, the definition of timing intervals after aSAH in the including studies differs from each other, which may account for potential heterogeneity. Second, in some original trials patients who died prematurely may be excluded from their analysis, prognostic factors such as different surgical approaches (clipping or intravascular coiling) (2), duration of loss of consciousness at the symptom onset of aSAH, clinical admission condition, aneurysmal size and location, amount of cisternal blood and drug using in perioperative management, could not be adequately extracted from each article. Besides, withdraw bias exited and the follow-up time length may not be so long in some cohort studies. Furthermore, many studies included in this paper were carried out in earlier times, whereas growing body of advanced literatures put more emphasis upon early intervention even ultra-early within 24 hours. Thus, corresponding bias may exist in this meta-analysis (29).

Future systematic analyses still require additional RCTs with stronger quality control, more vigorous experimental design, larger cohort sizes, longer follow-up periods and multicenter or international collaboration. Further basic researches of mechanisms concerning the change of cerebral blood flow, ICP and CPP after onset of aSAH and the concrete relationship among them still need to be exploited including in patients with poor grade. What an important role on earth does EBI play in possibly occurred re-bleeding, vasospasm and delayed brain injury (39)? Whether these changes could become our target of intervention still demands more research. Thus to better address these questions, further prospective studies are still warranted.

\section{- CONCLUSION}

Notwithstanding the methodological drawbacks, a cautious meta-analysis of 1 RCT and 33 cohort studies including 16,793 participants indicated that timing of surgery did not put a significant impact on surgical outcome, regardless of clinical condition at admission. Further subgroup analysis suggested a trend with more benefit for early intervention, which promoted, to a certain extent, a policy for early intervention as soon as possible. However, the long-term clinical outcome still needs further study, especially in this era of endovascular coiling. Therefore, particular attention should be paid to interpreting the results.

\section{- REFERENCES}

1. Abe K, Demizu A, Kamada K, Shimada Y, Sakaki T, Yoshiya I: Prostaglandin E1 and carbon dioxide reactivity during cerebral aneurysm surgery. Can J Anaesth 39: 247-252, 1992

2. Attenello FJ, Wang K, Wen T, Cen SY, Kim-Tenser M, Amar AP, Sanossian N, Giannotta SL, Mack WJ: Health disparities in time to aneurysm clipping/coiling among aneurysmal subarachnoid hemorrhage patients: A national study. World Neurosurg 82: 1071-1076, 2014
3. Ayer R, Zhang J: Connecting the early brain injury of aneurysmal subarachnoid hemorrhage to clinical practice. Turk Neurosurg 20: 159-166, 2010

4. Baltsavias GS, Byrne JV, Halsey J, Coley SC, Sohn MJ, Molyneux AJ: Effects of timing of coil embolization after aneurysmal subarachnoid hemorrhage on procedural morbidity and outcomes. Neurosurgery 47:1320-1329; discussion 1329-1331, 2000

5. Chyatte D, Fode NC, Sundt TM Jr: Early versus late intracranial aneurysm surgery in subarachnoid hemorrhage. J Neurosurg 69: 326-331, 1988

6. Dalbayrak S, Altas M, Arslan R: The effects of timing of aneurysm surgery on vasospasm and mortality in patients with subarachnoid hemorrhage. Acta Neurol Belg 111:317320, 2011

7. de Gans K, Nieuwkamp DJ, Rinkel GJ, Algra A: Timing of aneurysm surgery in subarachnoid hemorrhage: A systematic review of the literature. Neurosurgery 50: 336-340; discussion 340-332, 2002

8. de Oliveira JG, Beck J, Ulrich C, Rathert J, Raabe A, Seifert $\mathrm{V}$ : Comparison between clipping and coiling on the incidence of cerebral vasospasm after aneurysmal subarachnoid hemorrhage: A systematic review and meta-analysis. Neurosurg Rev 30: 22-30; discussion 30-21, 2007

9. Dorhout Mees SM, Molyneux AJ, Kerr RS, Algra A, Rinkel GJE: Timing of aneurysm treatment after subarachnoid hemorrhage: Relationship with delayed cerebral ischemia and poor outcome. Stroke 43: 2126-2129, 2012

10. Dorsch NW: Surgery for cerebral aneurysms. An eight-year experience. Med J Aust 141: 18-21, 1984

11. Dorsch NW, Besser M, Brazenor GA, Stuart GG: Timing of surgery for cerebral aneurysms: A plea for early referral. Med J Aust 150:183, 187-188, 1989

12. Ferch R, Pasqualin A, Barone G, Pinna G, Bricolo A: Surgical management of ruptured aneurysms in the eighth and ninth decades. Acta Neurochir (Wien) 145:439-445; discussion 445, 2003

13. Ferro JM, Canhão $P$, Peralta R: Update on subarachnoid haemorrhage. J Neurol 255:465-479, 2008

14. Golchin N, Ramak Hashem SM, Abbas Nejad E, Noormohamadi S: Timing of surgery for aneurysmal subarachnoid hemorrhage. Acta Med Iran 50: 300-304, 2012

15. Gupta SK, Ghanta RK, Chhabra R, Mohindra S, Mathuriya SN, Mukherjee KK, Umredkar AU, Singla N: Poor-grade subarachnoid hemorrhage: Is surgical clipping worthwhile? Neurol India 59: 212-217, 2011

16. Haibin T, Guangfu H, Zili L, Hailong F, Zhenyu W, Dongdong $Z$, Jian T, Jinping L: The impact of surgical timing on the management of aneurysms with acute hydrocephalus after aneurysmal subarachnoid hemorrhage. Turk Neurosurg 24: 385-390, 2014

17. Haley EC Jr, Kassell NF, Torner JC: The international cooperative study on the timing of aneurysm surgery. The North American experience. Stroke 23: 205-214, 1992

18. Ingall T, Asplund K, Mahonen M, Bonita R: A multinational comparison of subarachnoid hemorrhage epidemiology in the WHO MONICA stroke study. Stroke. 31(5):1054-1061,2000 
19. Javadpour $M$, Silver $N$ : Subarachnoid haemorrhage (spontaneous aneurysmal). Clin Evid (Online) 2008, 2008

20. Kassell NF, Adams HP Jr, Torner JC, Sahs AL: Influence of timing of admission after aneurysmal subarachnoid hemorrhage on overall outcome. Report of the cooperative aneurysm study. Stroke 12: 620-623, 1981

21. Kassell NF, Boarini DJ, Adams HP Jr, Sahs AL, Graf CJ, Torner JC, Gerk MK: Overall management of ruptured aneurysm: Comparison of early and late operation. Neurosurgery 9:120128, 1981

22. Kawakami Y, Shimamura Y: Cisternal drainage after early operation of ruptured intracranial aneurysm. Neurosurgery 20: 8-14, 1987

23. Kayama T, Yoshimoto T, Uchida K, Takaku A, Suzuki J: Intracranial saccular aneurysms-surgical results of 1,000 consecutive cases. Tohoku J Exp Med 126:117-124, 1978

24. Lawson MF, Chi YY, Velat GJ, Mocco JD, Hoh BL: Timing of aneurysm surgery: The International Cooperative Study revisited in the era of endovascular coiling. J Neurolnterv Surg 2: $131-134,2010$

25. Lee KC: Surgery of intracranial aneurysms at Yonsei University: 780 cases. Keio J Med 40: 1-5, 1991

26. Ljunggren B, Brandt L, Sundbarg G, Saveland H, Cronqvist S, Stridbeck $\mathrm{H}$ : Early management of aneurysmal subarachnoid hemorrhage. Neurosurgery 11: 412-418, 1982

27. Luo YC, Shen CS, Mao JL, Liang CY, Zhang Q, He ZJ: Ultraearly versus delayed coil treatment for ruptured poor-grade aneurysm. Neuroradiology 57: 205-210, 2015

28. Mahaney KB, Todd MM, Torner JC: Variation of patient characteristics, management, and outcome with timing of surgery for aneurysmal subarachnoid hemorrhage. J Neurosurg 114:1045-1053, 2011

29. Matias-Guiu JA, Serna-Candel C: Early endovascular treatment of subarachnoid hemorrhage. Interv Neurol 1: 5664, 2012

30. Milhorat TH, Krautheim M: Results of early and delayed operations for ruptured intracranial aneurysms in two series of 100 consecutive patients. Surg Neurol 26: 123-128, 1986

31. Miyaoka M, Sato K, Ishii S: A clinical study of the relationship of timing to outcome of surgery for ruptured cerebral aneurysms. A retrospective analysis of 1622 cases. J Neurosurg 79: 373378, 1993

32. Munoz-Guillen NM, Leon-Lopez R, Tunez-Finana I, CanoSanchez A: From vasospasm to early brain injury: New frontiers in subarachnoid haemorrhage research. Neurologia 28: 309-316, 2013

33. Nieuwkamp DJ, de Gans K, Algra A, Albrecht KW, Boomstra S, Brouwers PJ, Groen RJ, Metzemaekers JD, Nijssen PC, Roos YB, Tulleken CA, Vandertop WP, van Gijn J, Vos PE, Rinkel GJ: Timing of aneurysm surgery in subarachnoid haemorrhage-an observational study in The Netherlands. Acta Neurochir (Wien) 147: 815-821, 2005

34. Ohman J, Heiskanen O: Timing of operation for ruptured supratentorial aneurysms: A prospective randomized study. J Neurosurg 70: 55-60, 1989
35. Otani N, Nawashiro H, Wada K, Nagatani K, Takeuchi S, Kobayashi H, Osada H, Suzuki T, Shima K: Surgical results after primary decompressive craniectomy in poor-grade aneurysmal subarachnoid hemorrhage. Acta Neurochir Suppl 118: 269-272, 2013

36. Phillips TJ, Dowling RJ, Yan B, Laidlaw JD, Mitchell PJ: Does treatment of ruptured intracranial aneurysms within 24 hours improve clinical outcome? Stroke 42: 1936-1945, 2011

37. Qian Z, Peng T, Liu A, Li Y, Jiang C, Yang H, Wu J, Kang H, Wu Z: Early timing of endovascular treatment for aneurysmal subarachnoid hemorrhage achieves improved outcomes. Curr Neurovasc Res 11: 16-22, 2014

38. Ross N, Hutchinson PJ, Seeley H, Kirkpatrick PJ: Timing of surgery for supratentorial aneurysmal subarachnoid haemorrhage: Report of a prospective study. J Neurol Neurosurg Psychiatry 72: 480-484, 2002

39. Sabri M, Lass E, Macdonald RL: Early brain injury: A common mechanism in subarachnoid hemorrhage and global cerebral ischemia. Stroke Res Treat 2013:394036, 2013

40. Sano K: Grading and timing of surgery for aneurysmal subarachnoid haemorrhage. Neurol Res 16: 23-26, 1994

41. Seifert V, Stolke D, Trost HA: Timing of aneurysm surgery. Comparison of results of early and delayed surgical intervention. Eur Arch Psychiatry Neurol Sci 237: 291-297, 1988

42. Stein SC: Brief history of surgical timing: Surgery for ruptured intracranial aneurysms. Neurosurg Focus 11:E3, 2001

43. Tamasauskas A, Tamasauskas J, Bernotas G, Inao S, Yoshida $\mathrm{J}$ : Management of patients with ruptured cerebral aneurysms in hospital population of Lithuania. Acta Neurochir (Wien) 142: 51-59, 2000

44. Taneda M: The significance of early operation in the management of ruptured intracranial aneurysms-an analysis of 251 cases hospitalized within 24 hours after subarachnoid haemorrhage. Acta Neurochir (Wien) 63: 201-208, 1982

45. Tso MK, Macdonald RL: Subarachnoid hemorrhage: A review of experimental studies on the microcirculation and the neurovascular unit. Transl Stroke Res 5: 174-189, 2014

46. Tucker WS: The relationship between timing of surgery and operative complications in aneurysmal subarachnoid hemorrhage. Can J Neurol Sci 14: 84-87, 1987

47. van der Jagt M, Hasan D, Dippel DWJ, van Dijk EJ, Avezaat CJJ, Koudstaal PJ: Impact of early surgery after aneurysmal subarachnoid haemorrhage. Acta Neurol Scand 119:100-106, 2009

48. van der Schaaf I, Algra A, Wermer M, Molyneux A, Clarke M, van Gijn J, Rinkel G: Endovascular coiling versus neurosurgical clipping for patients with aneurysmal subarachnoid haemorrhage. Cochrane Database Syst Rev: CD003085, 2005

49. Weir B, Aronyk K: Management mortality and the timing of surgery for supratentorial aneurysm. J Neurosurg 54:146-150, 1981

50. Wong GKC, Poon WS, Chan MTV, Zee BCY: Intravenous magnesium sulphate for aneurysmal subarachnoid hemorrhage (IMASH) A randomized, double-blinded, placebocontrolled, multicenter phase III trial. Stroke 41(5):921-926, 2010 
51. Wong GKC, Boet R, Ng SCP, Chan M, Gin T, Zee B, Poon WS: Ultra-Early (within 24 hours) aneurysm treatment after subarachnoid hemorrhage. World Neurosurg 77: 311-315, 2012

52. Yamamoto K, Ezuka I, Takai N, Kakinuma K: Comparison of late and early stage surgery for ruptured intracranial aneurysms. Neurol Med Chir (Tokyo) 32:1-4, 1992
53. Yuksel S, Tosun YB, Cahill J, Solaroglu I: Early brain injury following aneurysmal subarachnoid hemorrhage: Emphasis on cellular apoptosis. Turk Neurosurg 22: 529-533, 2012

54. Zhang Q, Ma L, Liu Y, He M, Sun H, Wang X, Fang Y, Hui $\mathrm{XH}$, You C: Timing of operation for poor-grade aneurysmal subarachnoid hemorrhage: Study protocol for a randomized controlled trial. BMC Neurol 13: 108, 2013 